\title{
Developing of experimental combustion boiler with stationary fluidized bed and multifuels combustion
}

\author{
Marek Jadlovec ${ }^{1 *}$, and Stanislav Honus ${ }^{1}$ \\ ${ }^{1}$ VSB - Technical University of Ostrava, 17. listopadu 2172/15, Ostrava-Poruba, Czech Republic
}

\begin{abstract}
Due to the outdated higher requirements for reducing emissions of harmful substances in the combustion of fossil fuels and waste in particular, more and more research is needed, which will lead to the provision of various alternatives to influence the emerging pollutants into the atmosphere. This study deals with the development of experimental combustion units with a stationary fluidized bed with regulated parameters of primary and secondary air supply, performed fuel supply and flue gas parameters. Combustion is carried out in a bubbling stationary fluidized bed with a height of $100 \mathrm{~mm}$ and a diameter of $140 \mathrm{~mm}$. The fluidized bed consists of ST 54 glass sand with a mean grain size of $0.22 \mathrm{~mm}$. The basic purpose of the study is to describe the construction of the experimental unit with verification of its functionality. On the experimental equipment was realized experiments in terms of combustion various types of fuels, whether they are fossil fuels (coal), alternative fuels as straw pellets, sludge from wastewater treatment plants, sludge from paper mills or their combinations. Determination of temperature and pressure along the entire length of the unit is a device equipped with thermocouples and pressure sensors.
\end{abstract}

\section{Introduction}

Fluidized bed combustion is one of the three most basic types of solid fuel combustion. In practice, fluidized bed combustion units are experimental with output from single digit $\mathrm{kW}$ to dezens $\mathrm{kW}$ up to heating plants with output in hundreds $\mathrm{kW}$. [1] This study uses an experimental unit with a maximum heat output of $20 \mathrm{~kW}$. The main goal of the design of the experimental fluidized unit was to design it so that it is possible to change the combustion parameters and at the same time the type of fuel almost immediately. [2] This is the main advantage of the whole stand and that is its versatility. To achieve the required versatility, the unit must be equipped with the correct source of primary and secondary combustion air, as well as a sufficiently large smoke fan for proper exhaust of combustion products. Fluidized bed combustion is realized at temperatures up to $900^{\circ} \mathrm{C}$. [3] This fact has a positive effect on the formation of $\mathrm{NO}_{\mathrm{x}}$ compounds. Another advantage is the possibility of dosing the sorbent directly into the fluidized bed to reduce $\mathrm{SO}_{\mathrm{x}}$ emissions. However, this article focuses mainly on the combustion of alternative fuels that could replace fossil fuels. [4], [5], [6], [7]

\footnotetext{
* Corresponding author: marek.jadlovec@,vsb.cz
} 
The disadvantage of combustion such fuels in a stationary fluidized bed is the greater amount of ash that the fuels carry. This fact leads to the degradation of the fluidized bed after a certain time and thus to a change in the character of combustion.

This article briefly describes all the limitations and the way to deal with the transformation of the boiler to another type of fuel. Thermocouples, pressure sensors, flow regulators and flue gas analyzers are implemented in the boiler to assess the quality of this transformation. [8], [9]

\section{Experimental setup}

\subsection{Experimental device and analyses equipment}

The experimental unit is located on the premises of VŠB - TUO. As you can see in Figure 1, the dominant element of the whole device is the primary air blower with performance 57 $\mathrm{m}^{3} \mathrm{~N} /$ hod with pressure ratio 1,7 and with controllability in the range $0-100 \%$. A primary combustion air flow meter is included in the pipeline to measure the flow. Another technological device is the preheating of primary air with an output of $4 \mathrm{~kW}$, which can preheat the combustion air up to a temperature of $650^{\circ} \mathrm{C}$. The preheated air is distributed on a "grate" in this case a silicon filter disc with a diameter of $90 \mathrm{~mm}$, a thickness of $6 \mathrm{~mm}$ and a porosity of 16 micrometers. This is followed by a fluidized bed, which consists of glass sand ST 54 with a mean grain size of $0,22 \mathrm{~mm}$. A preview of the fluidized bed is shown in Figure 2, with its steady state height being $100 \mathrm{~mm}$. [10] The fluidized bed is surrounded by resistance heaters with a total output of $8,8 \mathrm{~kW}$, which have the task of heating the combustion chamber to the required temperature. Above the fluidized bed is a secondary air inlet, which is initiated by a LEISTER MISTRAL hot air blower with performance 24 $\mathrm{m}^{3} \mathrm{~N} /$ hod. This is followed by the flue gas tract itself, which is equipped with a cyclone separator, water cooler and especially a smoke fan with performance $300 \mathrm{~m}^{3} \mathrm{~N} / \mathrm{hod}$.

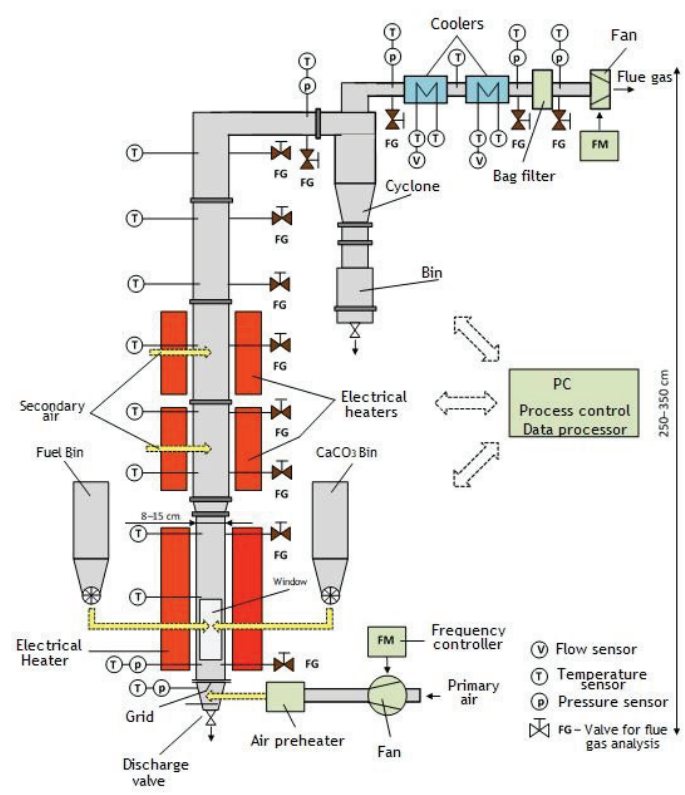

Fig. 1. Schematic view on experimental unit 
The chapter itself is fuel economy. For the transport of various materials, the device is equipped with two screw feeders with a pitch of $6 \mathrm{~mm}$ and $20 \mathrm{~mm}$ as you can see on Figure 3 (a), (b). The screw feeder is connected to the electric motor by means of a Hardy coupling. The transport capacity of the feeder with a pitch of $6 \mathrm{~mm}$ is up to $1,75 \mathrm{~kg} / \mathrm{hod}$ and for a pitch of $20 \mathrm{~mm}$ is up to $5,5 \mathrm{~kg} / \mathrm{hod}$. There are two possible systems of connecting the feeder, either state 1 Figure 4 (a), when the screw is led directly into the fluidized bed and state 2 Figure 4 (b), when the fuel is supplied indirectly into the fluidized bed by free fall through the connecting pipe. State 1 is more advantageous for fuels with a higher moisture content, where the fuel dries before entering the fluidized layer, and condition 2, for fuels with a higher heating value and lower moisture, where there is a risk that burns could occur during the dosing itself.

An interpretation of four temperatures $\mathrm{T}_{1}, \mathrm{~T}_{2}, \mathrm{~T}_{3}, \mathrm{~T}_{4}$ appears in the article. The temperature $T_{1}$ is measured at a height of $100 \mathrm{~mm}$ above the filter disc, while $T_{2}, T_{3}, T_{4}$ at a height of 300,500 and $700 \mathrm{~mm}$.

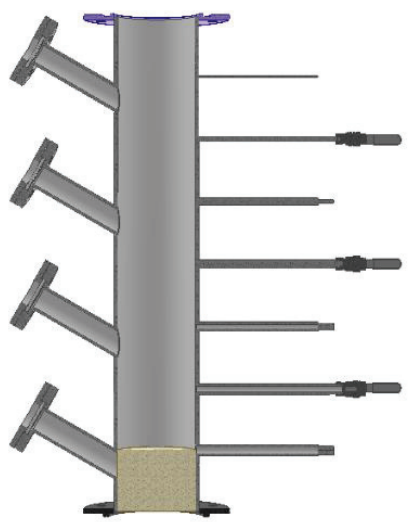

Fig. 2. Cross section of experimental unit with a view on fluidized bed

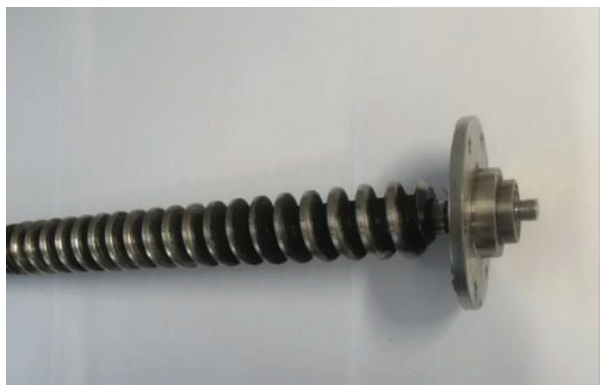

(a)

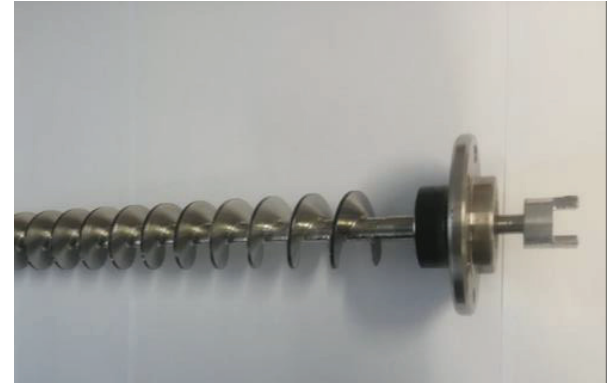

(b)

Fig. 3. Two types of screw conveyor (a) with a pitch $6 \mathrm{~mm}$ (b) with a pitch $20 \mathrm{~mm}$

Quantitative and qualitative evaluation of flue gases is performed by Gasmet DX4000 portable FTIR gas analyzer, see Figure 5 (c), which is able to analyze $\mathrm{CO}_{2}, \mathrm{CO}, \mathrm{N} 2 \mathrm{O}, \mathrm{NO}$, $\mathrm{NO}_{2}, \mathrm{SO}_{2}, \mathrm{NH}_{3}, \mathrm{HCl}, \mathrm{HF}, \mathrm{CH}_{4}, \mathrm{H}_{2} \mathrm{O}$ and $\mathrm{O}_{2}$. For additive analysis and control, a Testo 350 analyzer is available for the determination of $\mathrm{CO}, \mathrm{NO}, \mathrm{NO}_{2}, \mathrm{SO}_{2}, \mathrm{H}_{2} \mathrm{O}$, see Figure 5 (b). DURAG HM-1400 TRX Figure 5 (a) is available for $\mathrm{Hg}$ analysis in flue gas. [11], [12] 


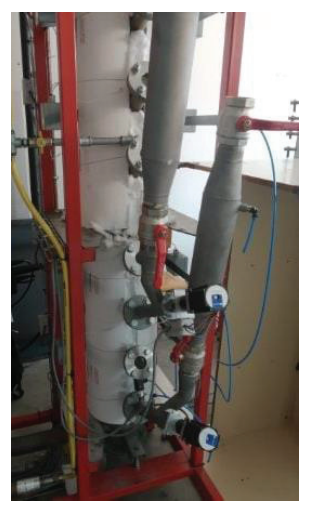

(a)

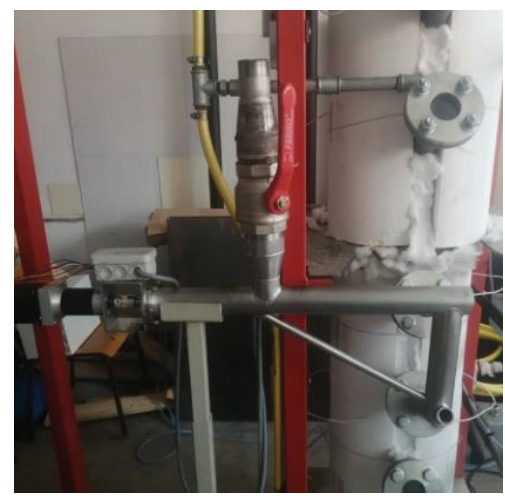

(b)

Fig. 4. Two types of fuel conveyor connection (a) directly to the fluidized bed (b) outside the fluidized bed

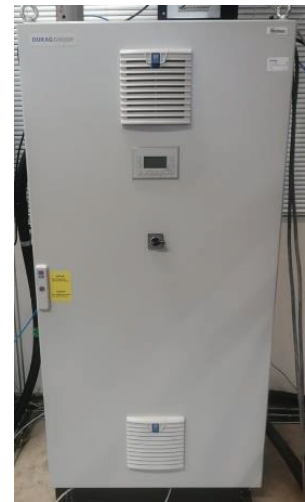

(a)

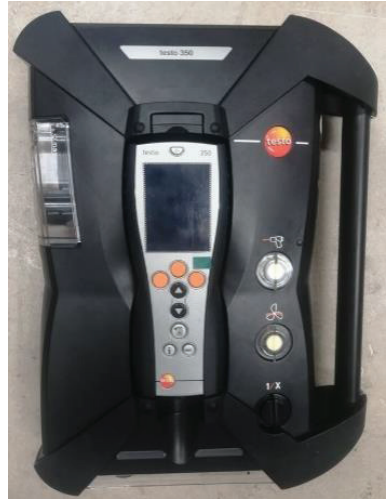

(b)

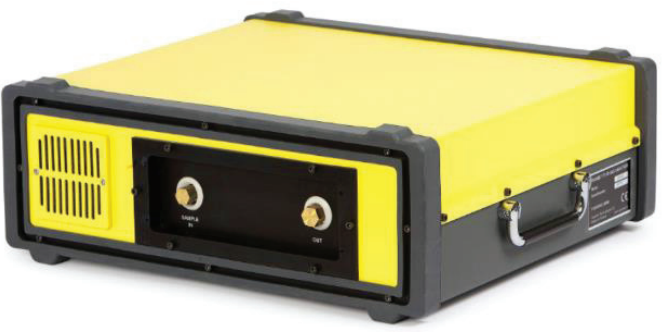

(c)

Fig. 5. Analyses equipment (a) DURAG HM-1400 TRX (b) Testo 350 (c) Gasmet DX4000 portable FTIR gas analyzer 


\subsection{Fuels Definition}

As mentioned in the paragraphs above, one of the most important features of the experimental unit is its versatility. This ability has been demonstrated in the combustion of multiple fuels. So far, six different types of fuels with different heating values and compositions have been burned in the combustion unit. These were straw pellets, sludge from wastewater treatment plants, sludge from paper mills their combination, lignite, and coal. Straw pellets can be seen in Figure 6. Figure 7 (a), (b), (c) shows a sludge from wastewater plants, a mixture of sludge from wastewater plants with a sludge from paper mills to a ratio of $4: 1$ and 2:1. Figure 8 (a) is lignite and Figure 8 (b) coal. [13]. Table 3 shows the elemental composition of the fuels used together with ash, moisture and heating value.

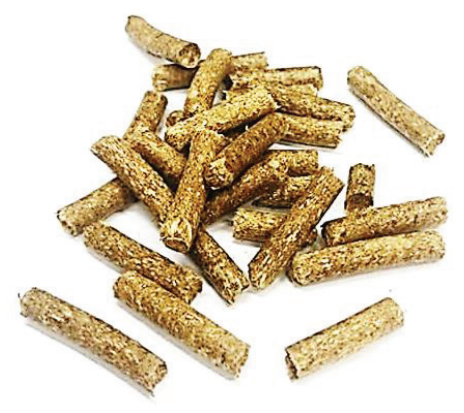

Fig. 6. Straw pellets

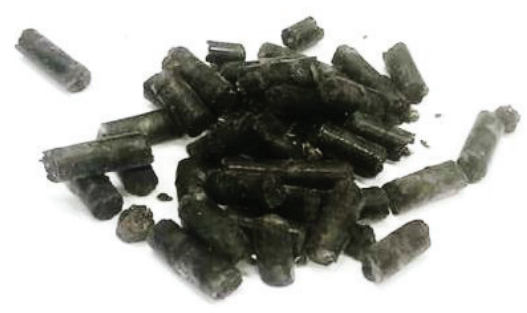

(a)

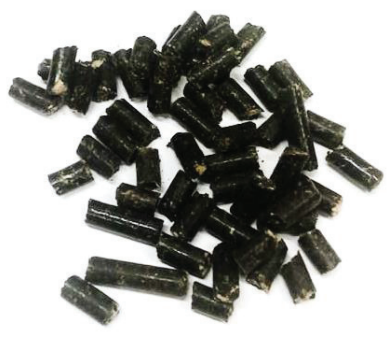

(b)

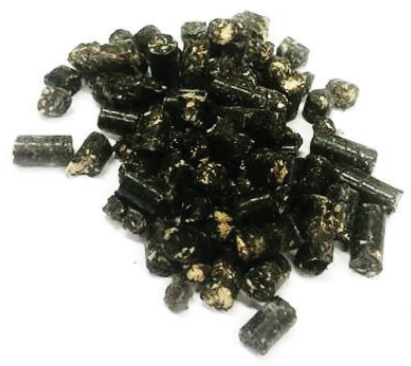

(c)

Fig. 7. (a) Sludge wastewater plants (b) Mix of sludge wastewater plants and paper mills sludge with ratio 4:1 (c) Mix of sludge wastewater plants and paper mills sludge with ratio 2:1 


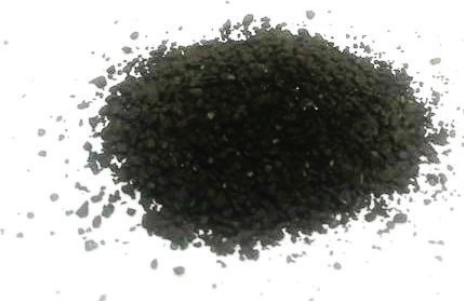

(a)

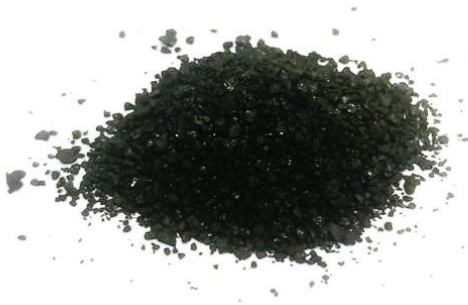

(b)

Fig. 8. (a) Lignite (b) Coal

Table 1. Ultimate analysis of fuels

\begin{tabular}{|l|l|l|l|l|l|l|}
\hline Parametr & \multicolumn{1}{|c|}{ Unit } & $\begin{array}{c}\text { Straw } \\
\text { pellets }\end{array}$ & $\begin{array}{c}\text { Sewage } \\
\text { sludge }\end{array}$ & $\begin{array}{c}\text { Paper mill } \\
\text { sludge }\end{array}$ & \multicolumn{1}{c|}{ Lignite } & \multicolumn{1}{c|}{ Coal } \\
\hline Carbon & [wt. \%] & $42,14 \pm 0,21$ & $29,07 \pm 0,15$ & $43,6 \pm 0,22$ & $65,8 \pm 0,33$ & $75,81 \pm 0,38$ \\
\hline Hydrogen & [wt. \%] & $5,14 \pm 0,10$ & $4,04 \pm 0,08$ & $4,2 \pm 0,08$ & $5,1 \pm 0,10$ & $4,62 \pm 0,09$ \\
\hline Sulphur & [wt. \%] & $0,12 \pm 0,004$ & $0,69 \pm 0,021$ & $1,3 \pm 0,039$ & $0,69 \pm 0,021$ & $0,33 \pm 0,010$ \\
\hline Nitrogen & [wt. \%] & $0,55 \pm 0,017$ & $2,93 \pm 0,088$ & $2,1 \pm 0,063$ & $1,03 \pm 0,031$ & $1,38 \pm 0,041$ \\
\hline Oxygen & [wt. \%] & 32,28 & 16,53 & 18,1 & 14,63 & 9,68 \\
\hline Moisture & [wt. \%] & $8,2 \pm 0,16$ & $21,8 \pm 0,44$ & $22,3 \pm 0,45$ & $10,59 \pm 0,21$ & $2,4 \pm 0,05$ \\
\hline Ash & [wt. \%] & $11,2 \pm 0,11$ & $24,94 \pm 0,25$ & $8,4 \pm 0,08$ & $2,14 \pm 0,02$ & $5,78 \pm 0,06$ \\
\hline $\begin{array}{l}\text { Heating } \\
\text { value }\end{array}$ & {$[\mathrm{MJ} / \mathrm{kg}]$} & $15,53 \pm 0,54$ & $9,83 \pm 0,34$ & $12,82 \pm 0,45$ & $26,8 \pm 0,94$ & $30,53 \pm 1,07$ \\
\hline
\end{tabular}

\section{Results}

\subsection{Calculation fluidization velocity}

Based on the correlation according to Broadhurst and Becker, the fluidization velocity is calculated. Table 2 defines the sand and air properties for the calculation. [14]

Table 2. Properties of air and sand

\begin{tabular}{|l|l|l|l|}
\hline Parametr & Unit & Air & Sand \\
\hline Diameter & {$[\mathrm{m}]$} & $\mathrm{x}$ & 0,00022 \\
\hline Density & {$\left[\mathrm{kg} / \mathrm{m}^{3}\right]$} & 2624 & 0,327 \\
\hline Temperature & {$[\mathrm{K}]$} & 1073,15 & $\mathrm{x}$ \\
\hline Viscosity & {$[\mathrm{Pa} . \mathrm{s}]$} & $4,26 \mathrm{E}-05$ & $\mathrm{x}$ \\
\hline Pressure & {$[\mathrm{kPa}]$} & 101,1 & $\mathrm{x}$ \\
\hline
\end{tabular}




$$
\begin{gathered}
A r=\frac{D_{p}^{3} \rho_{f}\left(\rho_{p}-\rho_{f}\right) g}{\mu^{2}} \\
\operatorname{Re}_{m f}^{2}=\frac{A r^{1,85}}{37,7 A r^{0,85}+242000\left(\frac{\rho_{p}}{\rho_{f}}\right)^{0,13}} \\
U_{m f}=\frac{\mu R e_{m f}}{D_{p} \rho_{f}}
\end{gathered}
$$

Where $A r$ is Archimedes number, $D p$ is particle diameter, $\rho_{p}$ is particle density, $\rho_{f}$ is fluid density, $g$ is gravitational constant, $\mu$ is dynamic viscosity, $R e$ is Reynolds number, $U_{m f}$ is minimum fluidization velocity.

The results are recorded in Table 3 .

TABLE 3. The resulting correlation values

\begin{tabular}{|l|l|l|}
\hline Parametr & Unit & Value \\
\hline $\mathrm{Ar}$ & {$[-]$} & 49,275 \\
\hline $\operatorname{Re}_{\mathrm{mf}}$ & {$[-]$} & 0,042 \\
\hline $\mathrm{U}_{\mathrm{mf}}$ & {$[\mathrm{m} / \mathrm{s}]$} & 0,025 \\
\hline
\end{tabular}

The actual velocity of the primary air at the entrance to the fluidization layer is $0,6-0,9 \mathrm{~m} / \mathrm{s}$, which is up to 30 times faster than the calculated minimum fluidization velocity. However, even at this speed, there is no flight of particles, due to the huge pressure drop on the filter disc and in the sand layer itself.

\subsection{Combustion Regime}

As you can see in Table 1, the elemental composition, the moisture ash content, and the related heating value is different for each fuel. The high diversity of heating value affects the combustion regime and therefore it is necessary to approach each fuel individually. It follows that an external heat source must be handled sensitively to heat the fluidized bed. For example, in the case of fuels with a heating value below 10, it is a problem to achieve autothermal combustion, so it is necessary to have the external heating switched on continuously or to use co-combustion with another fuel.

The graphs below show the course of temperatures along the height of the fluidized bed and the concentration of emission compounds in the flue gases of individual fuels. Concentrations were monitored $\mathrm{CO}, \mathrm{NO}_{\mathrm{x}}$ (sum of $\mathrm{NO}, \mathrm{N}_{2} \mathrm{O}$ a NO $\mathrm{NO}_{2}$ ), $\mathrm{HCl}, \mathrm{SO}_{2}, \mathrm{CO}_{2}, \mathrm{O}_{2}$ and total mercury. All experiments took place for 30 minutes after the onset of the combustion process.

Straw pellets are among the heatest fuels and therefore the temperature in the fluidized bed sometimes exceeded up to $900^{\circ} \mathrm{C}$. Figure 9 (a) shows that homogeneity was not sufficiently guaranteed, and unstable combustion occurred, indicating a slightly increasing $\mathrm{CO}$ and $100 \mathrm{mg} / \mathrm{m}^{3}$ limit. One of the causes of combustion instability was the larger size of the individual pellets. Their length was up to $40 \mathrm{~mm}$, which could lead to incorrect fuel dosing. 


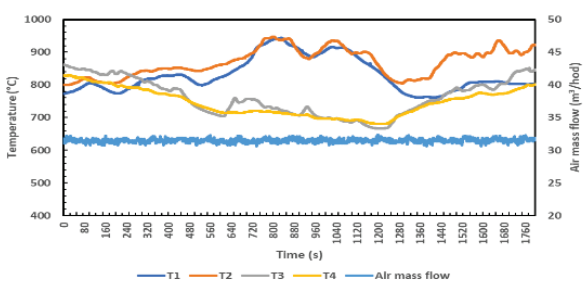

(a)

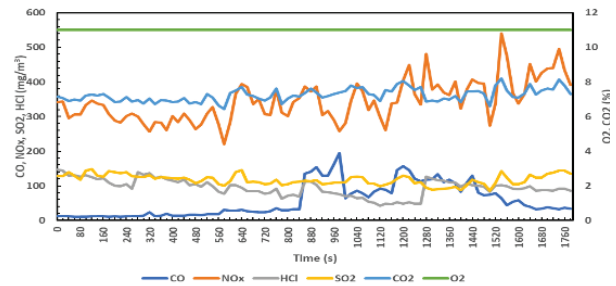

(b)

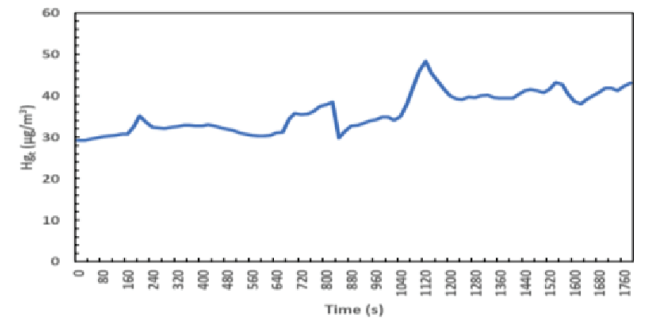

(c)

Fig. 9. Straw pellets combustion (a) The course of temperatures in the combustion chamber and air mass flow (b) Concentration of emission compounds of flue gases (c) Mercury concentration of flue gases

Sewage sludge is the fuel with the lowest heating value and therefore, as you can see from Figure 10 (a), the combustion temperature reached a maximum of $750{ }^{\circ} \mathrm{C}$, up to the upper floors of the combustion chamber. It follows that external heating had to be active throughout the combustion process. The fact that the temperature was higher in the upper floors of the combustion chamber means that it was in the upper floors that the generated $\mathrm{CO}$ burned down. Sewage sludge also has a higher mercury content, which is clearly seen in Figure 10 (c), where the maximum value of total mercury was $142 \mu \mathrm{g} / \mathrm{m}^{3} \mathrm{~N}$.

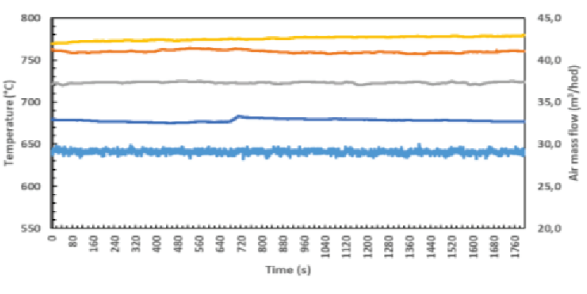

(a)

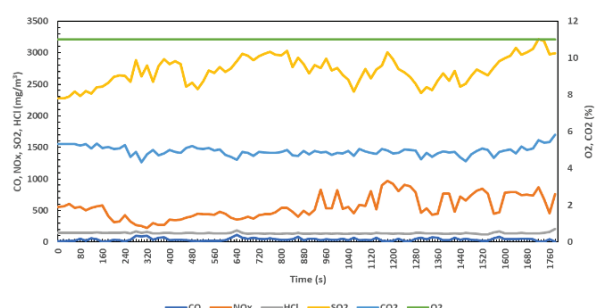

(b)

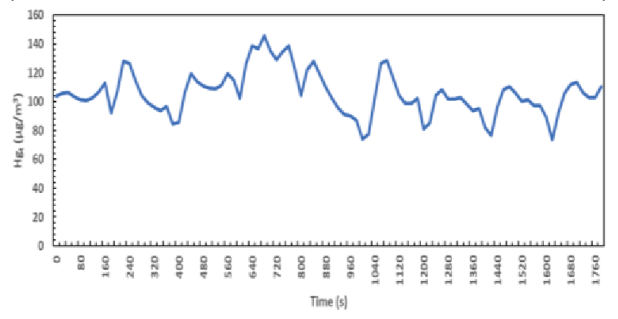

(c)

Fig. 10. Sewage sludge combustion (a) The course of temperatures in the combustion chamber and air mass flow (b) Concentration of emission compounds of flue gases (c) Mercury concentration of flue gases 


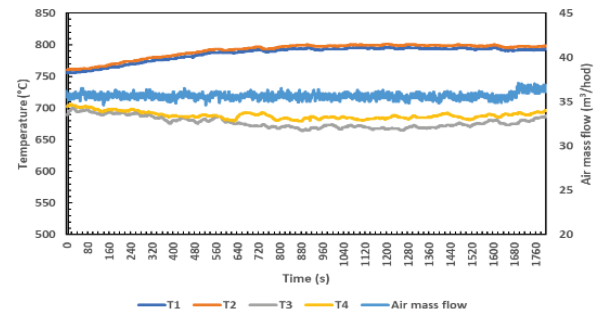

(a)

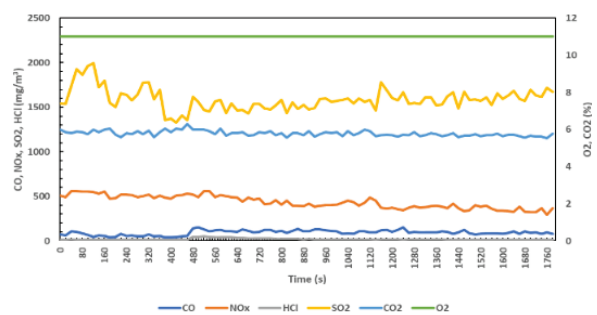

(b)

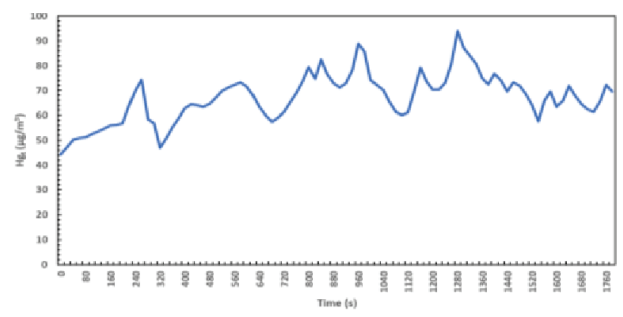

(c)

Fig. 11. Mix of sewage sludge and paper mills sludge with ratio 4:1 combustion (a) The course of temperatures in the combustion chamber and air mass flow (b) Concentration of emission compounds of flue gases (c) Mercury concentration of flue gases

This first mix with a ratio of 4:1 already has a higher heating value than pure sewage sludge, so the combustion takes place at a slightly higher temperature. Also, the ash content of this fuel is lower than that of a pure sewage sludge, which is why the fluidized bed is not so clogged with ash and thus degraded. The $\mathrm{NO}_{\mathrm{x}}$ value was slightly lower than the previous fuel, while the $\mathrm{SO}_{2}$ value was relatively significantly lower.

The second of the 2:1 mix has the lowest mercury content, as shown in Figure 12 (c). At the same time, it has the highest calorific value of all sludge incinerated, so it can be said that it is the most suitable for incineration. The combustion temperature is kept almost constant below $1000^{\circ} \mathrm{C}$, which is accurate for fluidized bed combustion.

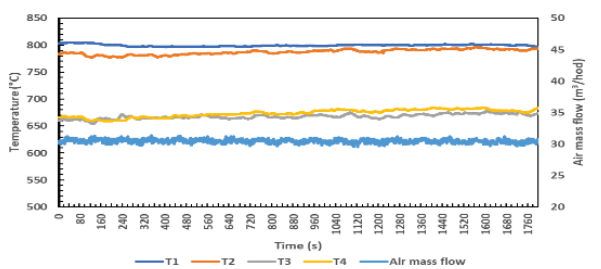

(a)

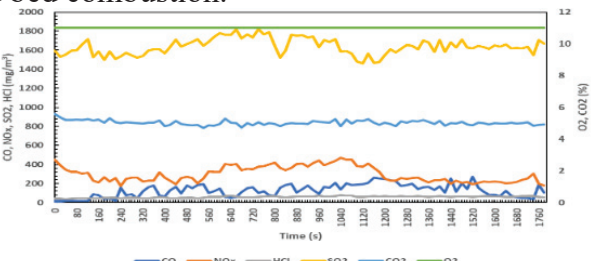

(b)

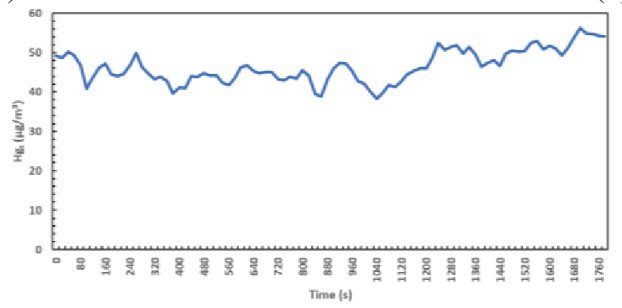

(c)

Fig. 12. Mix of sludge wastewater plants and paper mills sludge with ratio $2: 1$ combustion (a) The course of temperatures in the combustion chamber and air mass flow (b) Concentration of emission compounds of flue gases (c) Mercury concentration of flue gases 
Lignite is one of two types of coal that are combusted in the experimental unit. Thanks to its favorable granulometry $(0,71-2 \mathrm{~mm})$ and high heating value, it is a fuel with quality properties, as can be seen in Figure 13. Thanks to this granulometry, it is possible to use a screw conveyor with a lower pitch. The combustion temperature is almost constant, at the limit of $1000^{\circ} \mathrm{C}$ as well as pollutant emissions.

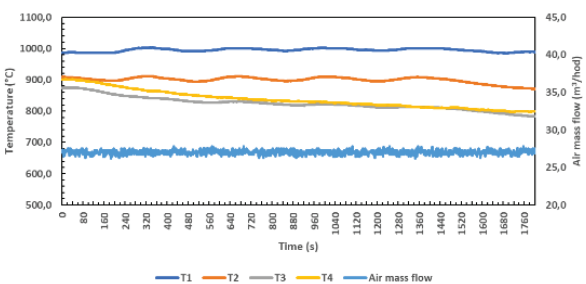

(a)

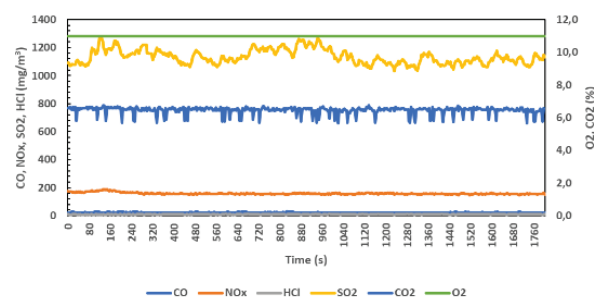

(b)

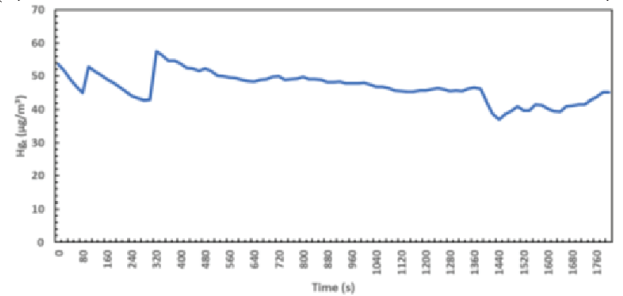

(c)

Fig. 13. Lignite combustion (a) The course of temperatures in the combustion chamber and air mass flow (b) Concentration of emission compounds of flue gases (c) Mercury concentration of flue gases

Coal is a fuel with the highest heating value, for which it is very difficult to maintain constant combustion. As you can see in Figure 14 (a), the primary combustion air flow had to be increased three times during combustion. This increase is due to the high consumption of oxygen, when the oxygen value decreased very rapidly and there was a possibility of a rapid increase in $\mathrm{CO}$.

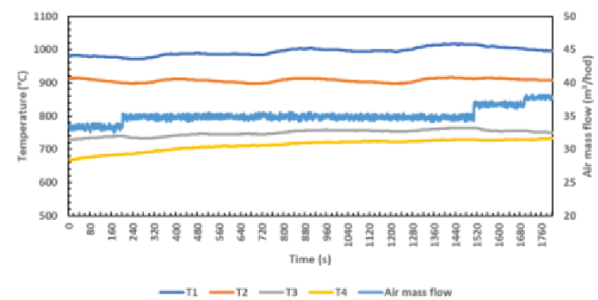

(a)

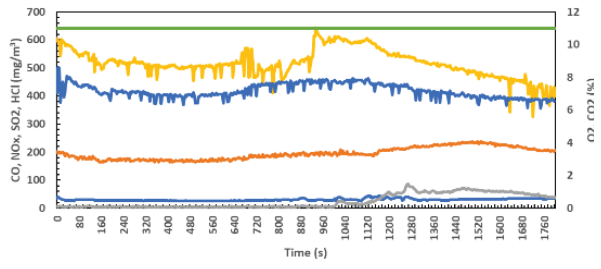

(b)

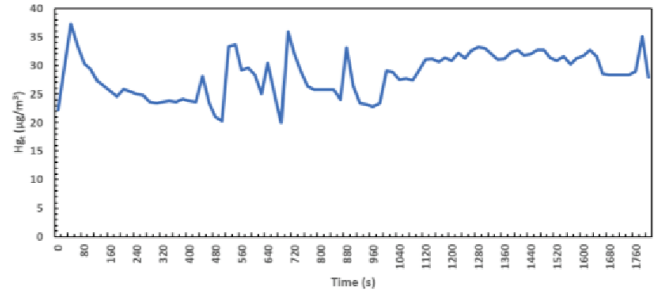

(c)

Fig. 14. Coal combustion (a) The course of temperatures in the combustion chamber and air mass flow (b) Concentration of emission compounds of flue gases (c) Mercury concentration of flue gases 
Table 4 summarizes the average combustion temperatures, air mass flow and concentration of emission compounds for each fuel.

TABLE 4. Conclusion of average combustion parameters for each fuel

\begin{tabular}{|l|l|l|l|l|l|l|l|}
\hline \multicolumn{1}{|c|}{ Parametr } & \multicolumn{1}{|c|}{ Unit } & $\begin{array}{c}\text { Straw } \\
\text { pellets }\end{array}$ & $\begin{array}{c}\text { Sewage } \\
\text { sludge }\end{array}$ & Mix 4:1 & Mix 2:1 & Lignite & Coal \\
\hline Temperature & {$\left[{ }^{\circ} \mathrm{C}\right]$} & 762,8 & 718,9 & 788,2 & 793,5 & 947,2 & 950,6 \\
\hline Air mass flow & {$\left[\mathrm{m}^{3} \mathrm{~N} / \mathrm{hod}\right]$} & 31,4 & 29,1 & 37,5 & 30,5 & 27,1 & 35,0 \\
\hline $\mathrm{CO}$ & {$\left[\mathrm{mg} / \mathrm{m}^{3} \mathrm{~N}\right]$} & 56,4 & 41,9 & 92,7 & 126,3 & 23,0 & 30,0 \\
\hline $\mathrm{NO}_{\mathrm{x}}$ & {$\left[\mathrm{mg} / \mathrm{m}^{3} \mathrm{~N}\right]$} & 345,0 & 554,4 & 435,8 & 295,8 & 158,2 & 194,5 \\
\hline $\mathrm{HCl}$ & {$\left[\mathrm{mg} / \mathrm{m}^{3} \mathrm{~N}\right]$} & 94,6 & 141,9 & 17,8 & 58,9 & 9,2 & 24,3 \\
\hline & {$\left[\mathrm{mg} / \mathrm{m}^{3} \mathrm{~N}\right]$} & 117,5 & 2721,6 & 1586,7 & 1637,1 & 1134,3 & 516,1 \\
\hline $\mathrm{SO}_{2}$ & {$[\%]$} & 7,5 & 5,3 & 5,7 & 5,0 & 6,4 & 7,2 \\
\hline $\mathrm{CO}_{2}$ & {$\left[\mu \mathrm{g} / \mathrm{m}^{3} \mathrm{~N}\right]$} & 36,1 & 105,9 & 52,0 & 46,5 & 46,8 & 28,4 \\
\hline $\mathrm{Hg}$ & & & & & & \\
\hline
\end{tabular}

\section{4 conclusion}

This article focused on the combustion of alternative and convection fuels in an experimental combustion unit with a stationary fluidized bed. For the correct design of the unit, calculations were performed to determine the flight speed. Six different types of fuel with variable calorific values in the range of $9,83-30,53 \mathrm{MJ} / \mathrm{kg}$ were tested on the unit. In all cases, the ability of equipment with certain limitations to burn fuel was demonstrated, both in the form of pellets and in bulk form. All measured values were interpreted in Figure 9 14. All average measured values were processed and interpreted in Table 4 for better clarity. Due to the reduction of the measurement deviation, only the so-called Mercury total was measured, as the sum of the elemental and oxidized forms of mercury. In such a small unit with a not very stable combustion, large inaccuracies occurred during the measurement of individual forms of mercury, which led to invalid dates. It has been found that the top two external electrical heaters need to be switched on throughout the combustion due to the afterburning of the $\mathrm{CO}$ produced. The biggest problem for the unit was more ash fuels, as over time the fluidized bed filled with ash, which led to its degradation.

This study was supported by the student project No. SP2021/110

\section{References}

1. YANG, Wen-ching (ed.). Handbook of fluidization and fluid-particle systems. CRC press, (2003).

2. OKA, Simeon. Fluidized bed combustion. CRC press, (2003).

3. ANTHONY, E. J. Fluidized bed combustion of alternative solid fuels; status, successes and problems of the technology. Progress in Energy and Combustion Science, (1995), 21.3: 239-268.

4. FANG, M., et al. Experimental study on rice husk combustion in a circulating fluidized bed. Fuel processing technology, (2004), 85.11: 1273-1282. 
5. WERTHER, J.; OGADA, Ti. Sewage sludge combustion. Progress in energy and combustion science, (1999), 25.1: 55-116.

6. MAGDZIARZ, Aneta, et al. Properties of ash generated during sewage sludge combustion: A multifaceted analysis. Energy, (2016), 113: 85-94.

7. KIJO-KLECZKOWSKA, Agnieszka, et al. Mechanisms and kinetics of granulated sewage sludge combustion. Waste Management, (2015), 46: 459-471.

8. HAGMAN, Henrik; BACKMAN, Rainer; BOSTROM, D. Co-combustion of animal waste, peat, waste wood, forest residues, and industrial sludge in a 50 MWth circulating fluidized-bed boiler: ash transformation, ash/deposit characteristics, and boiler failures. Energy \& fuels, (2013), 27.10: 5617-5627.

9. RAJCZYK, Rafał, et al. Co-combustion of municipal sewage sludge and hard coal on fluidized bed boiler WF-6. Archives of Environmental Protection, (2014), 40.3.

10. KOORNNEEF, Joris; JUNGINGER, Martin; FAAIJ, André. Development of fluidized bed combustion-An overview of trends, performance and cost. Progress in energy and combustion science, (2007), 33.1: 19-55.

11. BAK, Jimmy; CLAUSEN, Sønnik. FTIR emission spectroscopy methods and procedures for real time quantitative gas analysis in industrial environments. Measurement Science and Technology, (2001), 13.2: 150.

12. ERXLEBEN, Holger; RUZICKA, Jaromir. Atomic absorption spectroscopy for mercury, automated by sequential injection and miniaturized in lab-on-valve system. Analytical chemistry, (2005), 77.16: 5124-5128.

13. STASIAK, Mateusz, et al. Mechanical and combustion properties of sawdust-Straw pellets blended in different proportions. Fuel Processing Technology, (2017), 156: 366375.

14. BROADHURST, T. E.; BECKER, H. A. Onset of fluidization and slugging in beds of uniform particles. AIChE Journal, (1975), 21.2: 238-247. 